\title{
Low-dose green tea intake reduces incidence of atrial fibrillation in a Chinese population
}

\author{
Dong-Chen Liu', ${ }^{1,}$, Jian-Jun Yan ${ }^{1, *}$, You-Nan Wang ${ }^{2,}{ }^{*}$, Ze-Mu Wang ${ }^{1}$, Zhi-Yong Xie ${ }^{1}$, \\ Yao Ma ${ }^{1}$, Yang Yang ${ }^{1}$, Li Yang ${ }^{2}$ and Lian-Sheng Wang ${ }^{1}$ \\ 1 Department of Cardiology, the First Affiliated Hospital of Nanjing Medical University, Nanjing, Jiangsu, China \\ 2 Department of General Surgery, the First Affiliated Hospital of Nanjing Medical University, Nanjing, Jiangsu, China \\ * These authors have contributed equally to this work
}

Correspondence to: Lian-Sheng Wang, email: drlswang@njmu.edu.cn

Keywords: green tea; atrial fibrillation; Chinese; case control; low-dose

Received: May 05, $2016 \quad$ Accepted: September 20, 2016

Published: September 24, 2016

\section{ABSTRACT}

The aim of the present study was to assess the association between green tea intake and incidence of atrial fibrillation (AF) in a Chinese population. A total of 801 (mean age: 62 years; $56 \%$ male) subjects were enrolled: 401 AF patients and 400 controls. All subjects completed a questionnaire and the associations between their green tea drinking habits and incidence of AF were assessed using the odds ratio (OR) and binary logistic regression. After multivariate adjustment, green tea intake presented as a protective factor against the incidence of AF (OR: $0.349,95 \%$ CI: $0.253-$ $0.483, P<0.001)$. The green tea protection showed downward trend with increasing green tea intake ( $P$ for the trend $=0.001$ ). Low frequency, low concentration, shortterm tea consumption was classified as low-dose green tea intake. Green tea intake decreased the incidence of both paroxysmal AF (OR: $0.307,95 \%$ CI: $0.216-0.436, P$ $<0.001$ ) and persistent AF (OR: 0.355, 95\% CI: $0.261-0.482, P<0.001$ ) and may be associated with a decreased incidence of AF. This study suggests that low-dose green tea intake strongly protects against AF.

\section{INTRODUCTION}

Atrial fibrillation (AF) has become a global public health concern. At the end of the last century, the increasing prevalence of AF was mentioned by Braunwald in his Shattuck lecture [1-2]. According to data generated in North America, Britain, and Iceland, the prevalence of $\mathrm{AF}$ is approximately $0.5 \%$ to $1 \%$ in their general populations, respectively [3-5]. AF is the most common cardiac arrhythmia in adults, and is independently related to increased morbidity and mortality [6]. It also causes or exacerbates heart failure and ischemic stroke resulting from thromboembolism [7-10]. In recent years there has been a shift in focus from treatment to prevention and protection in practice guidelines related to $\mathrm{AF}$ [11-12].

The relationship between AF and consumption of certain beverages, such as those containing caffeine and alcohol, has been reported in several recent studies [13-19]. As the most popular beverage consumed around the world, tea intake per capita is approximately 0.12 L/y worldwide [20-21], and green tea was consumed predominantly in Asia [21-22]. Many studies report that green tea plays a protective role in the cardiovascular system [21, 23-26]. Our previous epidemiological studies demonstrate that green tea could protect against the development of coronary heart disease [23]. Moreover, we demonstrated using an in vitro experimental model that green tea extract could prevent and treat cardiovascular disease [27]. Habitual intake of tea also has protective effect on coronary heart disease and our meta-analysis revealed that certain teas might decrease the risk of coronary heart disease $[21,25,28]$. As such, we initiated a case-control study to evaluate the hypothesis that green tea intake is inversely related to the incidence of AF.

\section{RESULTS}

\section{Baseline characteristics}

Table 1 describes the baseline characteristics of the participants in our study. The AF patients and controls displayed significant differences in body mass index (BMI) 
Table 1: Baseline characteristics of the participants;

\begin{tabular}{|l|l|l|l|l|}
\hline Characteristics & AF $(\boldsymbol{N}=\mathbf{4 0 1})$ & $\begin{array}{l}\text { Controls } \\
(\mathbf{N = 4 0 0})\end{array}$ & $\begin{array}{l}\text { Statistical } \\
\text { parameter }\end{array}$ & $\boldsymbol{P}$ \\
\hline Age (years) & $63.00 \pm 1.24$ & $63.00 \pm 1.18$ & -0.026 & 0.979 \\
\hline Gender (F/M) & $160 / 241$ & $161 / 239$ & 0.010 & 0.920 \\
\hline BMI (kg/m2) & $24.32 \pm 3.54$ & $23.38 \pm 2.80$ & 4.163 & $<0.001$ \\
\hline Hypertension (Y/N) & $217 / 184$ & $122 / 278$ & 45.747 & $<0.001$ \\
\hline Systolic blood pressure & $131.6 \pm 24.3$ & $128.6 \pm 21.5$ & 23.712 & $<0.001$ \\
\hline Diastolic blood pressure & $78.7 \pm 12.1$ & $75.3 \pm 11.8$ & 8.403 & $<0.001$ \\
\hline Diabetes (Y/N) & $68 / 333$ & $58 / 342$ & 0.912 & 0.339 \\
Hyperlipoidemia (Y/N) & $90 / 311$ & $57 / 343$ & 8.973 & 0.003 \\
\hline CAD (Y/N) & $105 / 296$ & $64 / 336$ & 12.477 & $<0.001$ \\
\hline Smoke (Y/N) & $132 / 269$ & $111 / 289$ & 2.530 & 0.112 \\
\hline Drink (Y/N) & $144 / 257$ & $138 / 262$ & 0.175 & 0.676 \\
\hline Exercise (Y/N) & $195 / 206$ & $198 / 202$ & 0.061 & 0.805 \\
\hline Tea (Y/N) & $155 / 246$ & $242 / 158$ & 38.233 & $<0.001$ \\
\hline Y \%) & 38.65 & 60.5 & & \\
\hline AF, atr & & & & \\
\hline
\end{tabular}

$\mathrm{AF}$, atrial fibrillation; BMI, body mass index; CAD, coronary heart disease;

Table 2: Univariate logistic regression for influencing factors of atrial fibrillation;

\begin{tabular}{|c|c|c|c|}
\hline \multirow{2}{*}{ Characteristic } & \multicolumn{3}{|c|}{ All subjects } \\
\hline & OR & $95 \% \mathrm{CI}$ & $P$ \\
\hline Age & 1.200 & $0.903,1.594$ & 0.209 \\
\hline Sex $($ male $=1$. female $=0)$ & 1.015 & $0.765,1.346$ & 0.920 \\
\hline BMI & 2.755 & $1.966,3.861$ & $<0.001$ \\
\hline Hypertension $($ yes $=1$. no $=0)$ & 2.687 & $2.012,3.590$ & $<0.001$ \\
\hline Diabetes $($ yes $=1$. no $=0)$ & 1.204 & $0.822,1.763$ & 0.340 \\
\hline Hyperlipidemia $($ yes $=1$. no $=0$ ) & 1.741 & $1.208,2.510$ & 0.003 \\
\hline CAD $($ yes $=1$. no $=0)$ & 1.862 & $1.315,2.637$ & $<0.001$ \\
\hline Tea $($ yes $=1$. no $=0)$ & 0.411 & $0.310,0.546$ & $<0.001$ \\
\hline Smoking status (yes $=1$. no $=0$ ) & 1.278 & $0.944,1.728$ & 0.112 \\
\hline Drinking status (yes $=1$. no $=0$ ) & 1.064 & $0.796,1.422$ & 0.676 \\
\hline Exercise $($ yes $=1$. no $=0)$ & 0.966 & $0.732,1.274$ & 0.805 \\
\hline
\end{tabular}

1. AF, atrial fibrillation; BMI, body mass index; CAD, coronary heart disease;

$(P<0.001)$, hypertension $(P<0.001)$, hyperlipoidemia $(P$ $=0.003)$, and congestive heart failure $(P<0.001)$. The AF patient group had a significantly lower proportion of individuals who drank green tea $(38.65 \%)$, compared to the control group $(60.50 \%)(P<0.001)$.

\section{Univariate logistic regression analysis}

Univariate analysis of the variables between the patients and controls (Table 2) identified a significant association between AF and green tea consumption (OR: 0.411, 95\% CI: 0.310-0.546, $P<0.001)$. Moreover, patients with hypertension (OR: 2.687, 95\% CI: $2.012-$ 3.590, $P<0.001$ ), hyperlipoidemia (OR: $1.741,95 \% \mathrm{CI}$ : $1.208-2.510, P=0.003)$, or congestive heart failure (OR: $1.862,95 \%$ CI: $1.315-2.637, P<0.001)$ were more likely to suffer from AF. BMI (OR: $2.755,95 \%$ CI: 1.966-3.861, $P<0.001)$ was an additional risk factor for AF.

\section{Multivariate logistic regression analysis}

We performed a multivariate logistic regression to refine the variables that impact AF. Table 3 shows the results of adjusted $\mathrm{OR}$, respective confidence intervals at $95 \%$, and $\mathrm{p}$ value under the multivariate model, including variables of green tea intake, age, sex, BMI, exercise, smoking status, drinking status hypertension, hyperlipoidemia, congestive heart failure and diabetes. We found hypertension (OR: 2.330, 95\% CI: 1.679-3.233, $P<0.001$ ) and BMI (OR: 1.062, 95\% CI: 1.008-1.118, $P$ $=0.023)$ remained associated with an increased incidence of AF. Green tea intake (OR: 0.355, 95\% CI: 0.261-0.482, $P<0.001)$ remained an independent protective factor against AF in the whole population. 
Table 3: Multivariate logistic regression for factors influencing AF;

\begin{tabular}{|l|l|l|l|}
\hline Characteristics & OR & $\mathbf{9 5 \%}$ CI & $\boldsymbol{P}$ \\
\hline Age & 0.996 & $0.983-1.010$ & 0.594 \\
\hline Sex $($ male=1.female=0) & 1.101 & $0.757-1.601$ & 0.615 \\
\hline BMI & 1.062 & $1.008-1.118$ & 0.023 \\
\hline Hypertension(yes=1.no=0) & 2.330 & $1.679-3.233$ & $<0.001$ \\
\hline CAD(yes=1.no=0) & 1.466 & $0.992-2.164$ & 0.055 \\
\hline tea(yes=1.no=0) & 0.349 & $0.253-0.483$ & $<0.001$ \\
\hline Hyperlipidemia(yes=1.no=0) & 1.162 & $0.765-1.765$ & 0.481 \\
\hline Diabetes(yes=1.no=0) & 0.891 & $0.584-1.360$ & 0.593 \\
\hline exerise(yes=1.no=0) & 1.172 & $0.974-1.410$ & 0.093 \\
\hline Smoking status (yes=1.no=0) & 1.235 & $0.978-1.559$ & 0.076 \\
\hline Drinking status (yes=1.no=0) & 1.008 & $0.784-1.296$ & 0.949 \\
\hline
\end{tabular}

1. AF, atrial fibrillation; BMI, body mass index; CAD coronary artery disease;

2. Multivariate logistic regression for age, gender, body mass index, smoking status, alcohol use, physical activity, hypertension, hyperlipidemia, diabetes mellitus, and CAD in the analysis.

Table 4: Relationship between green tea intake and risk of AF;

\begin{tabular}{|c|c|c|c|c|c|c|}
\hline Characteristics & \begin{tabular}{|l} 
Controls \\
$(\mathrm{N}=400)$
\end{tabular} & Atrial fibrillation $(N=401)$ & Crude OR & $P$ & Adjusted OR & $P$ \\
\hline \multicolumn{7}{|l|}{$\mathrm{Tea}(\mathrm{Y} / \mathrm{N})$} \\
\hline 0 & 158 & 246 & 1 & & & \\
\hline 1 & 242 & 155 & $\begin{array}{l}0.411 \\
(0.310-0.546) \\
\end{array}$ & $<0.001$ & \begin{tabular}{|l|}
0.385 \\
$(0.286-0.519)$ \\
\end{tabular} & $<0.001$ \\
\hline \multicolumn{7}{|l|}{ Frequency } \\
\hline None & 158 & 246 & 1 & & 1 & \\
\hline Low & 37 & 23 & \begin{tabular}{|l|}
0.399 \\
$(0.229-0.697)$ \\
\end{tabular} & 0.001 & \begin{tabular}{|l|}
0.398 \\
$(0.223-0.712)$ \\
\end{tabular} & 0.002 \\
\hline Moderate & 188 & 115 & $\begin{array}{l}0.393 \\
(0.289-0.697)\end{array}$ & $<0.001$ & \begin{tabular}{|l|}
0.364 \\
$(0.264-0.502)$
\end{tabular} & $<0.001$ \\
\hline Long & 17 & 17 & \begin{tabular}{|l|}
0.642 \\
$(0.319-1.295)$ \\
\end{tabular} & 0.216 & \begin{tabular}{|l|}
0.594 \\
$(0.285-1.239)$ \\
\end{tabular} & 0.165 \\
\hline $\mathrm{P}$ for the trend & & & & $<0.001$ & & $<0.001$ \\
\hline \multicolumn{7}{|l|}{ Concentration } \\
\hline None & 158 & 246 & 1 & & 1 & \\
\hline Low & 193 & 70 & \begin{tabular}{|l|}
0.233 \\
$(0.166-0.337)$ \\
\end{tabular} & $<0.001$ & \begin{tabular}{|l|}
0.223 \\
$(0.156-0.317)$ \\
\end{tabular} & $<0.001$ \\
\hline Moderate & 23 & 34 & \begin{tabular}{|l|}
0.949 \\
$(0.539-1.672)$ \\
\end{tabular} & 0.857 & \begin{tabular}{|l|}
0.844 \\
$(0.469-1.159)$ \\
\end{tabular} & 0.572 \\
\hline High & 26 & 51 & \begin{tabular}{|l}
1.260 \\
$(0.754-2.104)$
\end{tabular} & 0.377 & \begin{tabular}{|l}
1.140 \\
$(0.671-1.937)$ \\
\end{tabular} & 0.628 \\
\hline $\mathrm{P}$ for the trend & & & & 0.320 & & 0.153 \\
\hline \multicolumn{7}{|l|}{ Duration } \\
\hline Never & 158 & 246 & 1 & & 1 & \\
\hline $\begin{array}{l}\text { Short } \\
\text { Moderate } \\
\text { Long }\end{array}$ & $\begin{array}{l}61 \\
122 \\
59\end{array}$ & $\begin{array}{l}24 \\
63 \\
68\end{array}$ & $\begin{array}{l}0.253 \\
(0.151-0.422) \\
0.333 \\
(1.231-0.477) \\
0.743 \\
(0.495-1.106) \\
\end{array}$ & $\begin{array}{l}<0.001 \\
<0.001 \\
0.148\end{array}$ & \begin{tabular}{|l|}
0.271 \\
$(0.160-0.462)$ \\
0.319 \\
$(0.218-0.465)$ \\
0.624 \\
$(0.408-0.953)$ \\
\end{tabular} & $\begin{array}{l}<0.001 \\
<0.001 \\
0.029\end{array}$ \\
\hline $\mathrm{P}$ for the trend & & & & $<0.001$ & & $<0.001$ \\
\hline
\end{tabular}

$\mathrm{AF}$, atrial fibrillation; $\mathrm{OR}$, odds ratio; $\mathrm{CI}$, confidence interval;

1. In frequency, group was categorized as low ( $<1$ cup/day) moderate (1cup/day) and high ( $>1$ cup/day).

2. In concentration, group was categorized as low (tea leaves were $<25 \%$ of the volume of the cup), moderate (tea leaves were $25-50 \%$ of the volume of the cup) and high (tea leaves were $>50 \%$ of the volume of the cup).

3. In duration, group was categorized as short (1-15Y) moderate (16-30Y) and long $(>30 \mathrm{Y})$.

4. Adjustment for age, gender, body mass index, smoking status, alcohol use, physical activity, hypertension, hyperlipidemia, diabetes mellitus, and CAD in the analysis. 


\section{Relationship between green tea and incidences of AF}

To further confirm the relationship between $\mathrm{AF}$ and green tea, we reviewed additional parameters in the questionnaire. We documented the characteristics of the participants' green tea intake, including frequency, concentration, and duration (length of time consistently drinking tea) as described in Table 4. To the best of our knowledge, green tea intake played a protective role against the incidence of AF with a crude OR of $0.411(P$ $<0.001)$ and an adjusted OR of $0.385(P<0.001)$ after adjustment for age, gender, BMI, smoking status, alcohol use, physical activity, hypertension, hyperlipidemia, diabetes mellitus, and coronary artery disease (CAD). Participants in the low frequency group (adjusted OR: 0.398, 95\% CI: 0.223-0.712) had a decreased incidence of $\mathrm{AF}$, compared to those in the high frequency group (adjusted OR: 0.594, 95\% CI: 0.285-1.239). Moreover, a dose-response relation was clearly observed (P for the linear trend $<0.001)$. A similar dose-response relation was found with duration ( $\mathrm{P}$ for the trend $<0.001$ ). In the concentration groups, no clear dose-response relation was observed (adjusted OR: 1.140, 95\% CI: 0.671-1.937), even though the low concentration group showed a protective effect (adjusted OR: 0.223, 95\%CI: 0.156-0.317, $P<$ 0.001 ), which suggested low concentration green tea intake decreases the incidence of AF.

In order to further explore the relationship between dose of green tea intake and $\mathrm{AF}$, the green tea drinkers were scored and grouped in terms of duration, frequency and concentration of green tea intake. The frequency of green tea intake was rated on a 3-point scale ranging from low $=$ "1" to high $=$ " $3 "$, the same to concentration and duration accordingly. According to the final score, the green tea drinker was divided into 7 groups ranging from "3" to " 9 ". The green tea protection showed downward trend with increasing green tea intake $(P$ for the trend $<$ 0.001 ) ranging from " 3 " to " 9 ".

To explore differences in consumption of green tea among patients with different types of AF, we evaluated the baseline characteristics of our cohort, presented in Table 6. Significant differences in age $(P<0.001)$, BMI $(P<0.001)$, hypertension $(P=0.001)$, hyperlipoidemia $(P=0.003)$, and congestive heart failure $(P<0.001)$ were observed among the $3 \mathrm{AF}$ types. Specifically, permanent AF patients were more likely to be older with lower BMI.

Among the 240 patients with paroxysmal AF, 81 drank green tea. The frequency, concentration, and duration of green tea consumption and multivariableadjusted associations between green tea intake and paroxysmal AF are described in Table 7. Interestingly, we found green tea intake is a protective factor against paroxysmal AF with a crude OR of 0.333 (95\% CI, 0.238 $0.465, P<0.001)$ and an adjusted OR of $0.307(95 \% \mathrm{CI}$, $0.216-0.436, P<0.001)$. Notably, significant associations were observed between the frequency, concentration, and duration of green tea intake and paroxysmal $\mathrm{AF}$ (adjusted $P$ for trend $<0.001$ for frequency, $P=0.005$ for concentration, $P<0.001$ for duration).

In regard to persistent AF, 24 green tea drinkers and 48 non-tea drinkers are described in Table 8. Using exploratory analyses, we observed that green tea was associated with a protective effect for persistent $\mathrm{AF}$ patients (adjusted OR: 0.304, 95\% CI: 0.175-0.527, $P$ $<0.001)$. Furthermore, linear trend associations were revealed for frequency (adjusted $P$ for trend $<0.001$ ), concentration (adjusted $\mathrm{P}$ for trend $=0.001$ ) and duration (adjusted $\mathrm{P}$ for trend $=0.002$ ) with persistent AF.

Among different frequencies, concentrations, and durations of tea intake, the ORs were all less than 1, which suggests that the probabilities of paroxysmal AF and persistent AF in the tea group were less than in the nontea group. There was no statistical link between permanent $\mathrm{AF}$ and tea drinking.

\section{DISCUSSION}

\section{Principal study}

Herein, we present a case-control study evaluating the associations between green tea intake and the incidence of AF in a Chinese population. We observed a statistically significant relationship between green tea intake and reduced incidence of AF following multivariable adjustment.

The results of our study suggest that green tea intake might decrease the incidence of AF in accordance with a previous report [29]. Coronary heart disease is often considered to be an independent factor affecting the atrial fibrillation. Wang ZM et al reported a tentative association of green tea consumption with a reduced risk of CAD in a meta-analysis [21]. Pang et al provided evidence in the meta-analyses, included 9 studies and 259,267 individuals, that green tea intake is associated with favorable outcomes with respect to risk of cardiovascular diseases, myocardial infarction and stroke [30]. Hypertension is commonly thought to increase the incidence of atrial fibrillation. Greyling et al reported a reduction in blood pressure after tea intake in the meta-analysis by summaring evidence from 11 randomized controlled intervention studies including 378 subjects, [31]. It has been well established that atrial remodeling is a mechanism for promoting $\mathrm{AF}$ [32]. The processes of oxidative stress and inflammation could play important roles in increased fibrosis and inflammation and/or alteration of electrophysiology which could directly result in AF [7, 8]. In fact, these associations have been validated in numerous clinical and experimental studies [33-39]. Patients with AF exhibit high NF-kappaB activity, high concentrations of TNF-alpha and IL-6, 
Table 5: Relations between doses of Green tea intake and AF;

\begin{tabular}{|c|c|c|c|c|}
\hline Groups & $\begin{array}{c}\text { Controls } \\
(\boldsymbol{N}=\mathbf{2 4 2})\end{array}$ & Atrial fibrillation $(\boldsymbol{N}=\mathbf{1 5 5})$ & $\begin{array}{c}\text { OR } \\
\mathbf{9 5 \%} \mathbf{C I}\end{array}$ & \multicolumn{1}{c|}{} \\
\hline 0 & 158 & 246 & 1 & $<0.001$ \\
\hline 3 & 22 & 3 & $0.088(0.026-0.297)$ & $<0.001$ \\
\hline 4 & 45 & 18 & $0.257(0.144-0.460)$ & $<0.001$ \\
\hline 5 & 92 & 34 & $0.237(0.153-0.369)$ & $<0.001$ \\
\hline 6 & 47 & 39 & $1.164(0.612-2.213)$ & 0.643 \\
\hline 7 & 16 & 29 & $1.020(0.538-1.932)$ & 0.951 \\
\hline 8 & 17 & 27 & $1.070(0.252-4.542)$ & 0.926 \\
\hline 9 & 3 & 5 & & $<0.001$ \\
\hline
\end{tabular}

1. AF, atrial fibrillation; OR, odds ratio; $\mathrm{CI}$, confidence interval;

2 . The frequency of green tea intake was rated on a 3-point scale ranging from low = " 1 " to high = " 3 ", the same to concentration and duration accordingly.

3. According to the final score, the green tea drinker was divided into 7 groups ranging from " 3 " to "9.

Table 6: Characteristics for different atrial fibrillation groups;

\begin{tabular}{|c|c|c|c|c|c|c|}
\hline Characteristics & \begin{tabular}{|l|} 
Paroxysmal \\
AF $(N=240)$
\end{tabular} & \begin{tabular}{|l|}
$\begin{array}{l}\text { Persistent AF } \quad(N= \\
72)\end{array}$ \\
\end{tabular} & $\begin{array}{l}\text { Permanent AF }(N= \\
\text { 89) }\end{array}$ & \begin{tabular}{|l|} 
Controls \\
$(N=400)$
\end{tabular} & \begin{tabular}{|l|} 
Statistical \\
parameter
\end{tabular} & $P$ \\
\hline Tea $(\mathrm{Y} / \mathrm{N})$ & $81 / 159$ & $24 / 48$ & $50 / 39$ & $242 / 158$ & 52.292 & $<0.001$ \\
\hline Age (years) & $61.00 \pm 1.26$ & $61.00 \pm 1.19$ & $67.00 \pm 1.13$ & $63.00 \pm 1.18$ & 6.098 & $<0.001$ \\
\hline Gender (F/M) & $99 / 141$ & $31 / 41$ & $30 / 59$ & $161 / 239$ & 1.912 & 0.591 \\
\hline BMI (kg/m2) & $24.34 \pm 3.69$ & $24.93 \pm 2.96$ & $23.76 \pm 3.52$ & $23.38 \pm 2.80$ & 7.609 & $<0.001$ \\
\hline Hypertension $(\mathrm{Y} / \mathrm{N})$ & $125 / 115$ & $40 / 32$ & $52 / 37$ & $122 / 278$ & 46.892 & $<0.001$ \\
\hline $\begin{array}{l}\text { Diabetes(Y/N) } \\
\text { Hyperlipoidemia } \\
(\mathrm{Y} / \mathrm{N}) \\
\end{array}$ & $\begin{array}{l}37 / 203 \\
63 / 177\end{array}$ & $\begin{array}{l}12 / 60 \\
16 / 56\end{array}$ & $\begin{array}{l}19 / 70 \\
11 / 78\end{array}$ & $\begin{array}{l}58 / 342 \\
57 / 343\end{array}$ & \begin{tabular}{|l|}
2.641 \\
17.336
\end{tabular} & $\begin{array}{l}0.450 \\
0.001\end{array}$ \\
\hline $\mathrm{CAD}(\mathrm{Y} / \mathrm{N})$ & $63 / 177$ & $11 / 61$ & $31 / 58$ & $64 / 336$ & 21.620 & $<0.001$ \\
\hline Smoke (Y/N) & $81 / 159$ & $18 / 54$ & $33 / 56$ & $111 / 289$ & 5.474 & 0.140 \\
\hline Drink $(\mathrm{Y} / \mathrm{N})$ & $88 / 152$ & $27 / 45$ & $29 / 60$ & $138 / 262$ & 0.746 & 0.862 \\
\hline Exercise $(\mathrm{Y} / \mathrm{N})$ & $115 / 125$ & $38 / 34$ & $42 / 47$ & $198 / 202$ & 0.679 & 0.878 \\
\hline
\end{tabular}

$\mathrm{AF}$, atrial fibrillation; BMI, body mass index; CAD, coronary heart disease;

severe lymphomonocyte infiltration, and fibrosis [40]. Wu et al reported increased C-reactive protein (CRP), interleukin-6 (IL-6), and tumor necrosis factor-alpha were significantly associated with AF risk [41-42]. Catechins constitute $80-90 \%$ of total flavonoids, the main ingredient of green tea, with epigallocatechin gallate (EGCG) being the most abundant (48-55\%) [24, 43]. EGCG has been demonstrated to play an important anti-oxidative, antiproliferative, and anti-inflammatory role in cardiovascular diseases [44]. EGCG has also been reported to have anti$\mathrm{NF}-\kappa \mathrm{B}$ transactivation activity in chronic inflammation [45], preventing PCB-126-induced endothelial cell inflammation via epigenetic modifications of NF- $\mathrm{KB}$ target genes in human endothelial cells [46]. Ras et al by reported a meta-analysis moderate consumption of tea substantially enhances endothelial-dependent vasodilation [47].Our previous investigation reported that EGCG significantly suppresses the TNF-alpha-induced MCP-1 protein and mRNA expression, thereby inhibiting inflammation and anti-oxidative stress [27]. Zhu et al reported that EGCG protected against atrial electrical and structural remodeling in a rabbit RAP model by attenuating inflammation and oxidative stress [48]. Therefore, EGCG could be the most important contributor to the beneficial effect of green tea on $\mathrm{AF}$ incidence.

In the present study, we analyzed the tea drinking habits of a Chinese population. Our results demonstrate that frequency and duration of drinking green tea are equivocally associated with a decreased incidence of AF. The results also suggest that excessive green tea intake weakens the protective effect. We speculated another component of green tea might reduce the effect of EGCG. Green tea contains large quantities of caffeine which is not directly associated with decreased incidence of AF [13, 49-50]. High frequency-high concentration, or long-term green tea consumption may lead to high cumulative doses of caffeine which might contribute to an incidence of AF [51]. In the long duration and high frequency groups, a negative correlation, corresponding to the increase of OR value, indicates that the protective effect is weakened. The high tea concentration group has an OR greater than 1 , indicating that the effect is not protective but harmful. 
Table 7: Relationship between green tea intake and risk of paroxysmal AF;

\begin{tabular}{|c|c|c|c|c|c|c|}
\hline Groups & \begin{tabular}{|l|} 
Controls \\
$(N=\mathbf{4 0 0})$
\end{tabular} & Paroxysmal AF $(N=240)$ & Crude OR & $P$ & Adjusted OR & $P$ \\
\hline \multicolumn{7}{|l|}{ Tea $(\mathrm{Y} / \mathrm{N})$} \\
\hline 0 & 158 & 159 & 1 & & & \\
\hline 1 & 242 & 81 & $\begin{array}{l}0.333 \\
(0.238-0.465) \\
\end{array}$ & $<0.001$ & $\begin{array}{l}0.307 \\
(0.216-0.436)\end{array}$ & $<0.001$ \\
\hline \multicolumn{7}{|l|}{ Frequency } \\
\hline None & 158 & 159 & 1 & & 1 & \\
\hline Low & 37 & 11 & \begin{tabular}{|l|}
0.295 \\
$(0.146-0.600)$ \\
\end{tabular} & 0.001 & $\begin{array}{l}0.301 \\
(0.145-0.625)\end{array}$ & 0.001 \\
\hline Moderate & 188 & 62 & \begin{tabular}{|l|}
0.328 \\
$(0.228-0.471)$ \\
\end{tabular} & $<0.001$ & $\begin{array}{l}0.299 \\
(0.205-0.437)\end{array}$ & $<0.001$ \\
\hline High & 17 & 8 & $\begin{array}{l}0.468 \\
(0.196-1.115)\end{array}$ & 0.086 & $\begin{array}{l}0.410 \\
(0.165-1.018)\end{array}$ & 0.055 \\
\hline $\mathrm{P}$ for the trend & & & & $<0.001$ & & $<0.001$ \\
\hline \multicolumn{7}{|l|}{ Concentration } \\
\hline None & 158 & 159 & 1 & & 1 & \\
\hline Low & 193 & 37 & \begin{tabular}{|l|}
0.191 \\
$(0.126-0.288)$ \\
\end{tabular} & $<0.001$ & $\begin{array}{l}0.179 \\
(0.116-0.275) \\
\end{array}$ & $<0.001$ \\
\hline Moderate & 23 & 21 & $\begin{array}{l}0.907 \\
(0.483-1.706) \\
\end{array}$ & 0.763 & $\begin{array}{l}0.851 \\
(0.442-1.638)\end{array}$ & 0.629 \\
\hline High & 26 & 23 & $\begin{array}{l}0.897 \\
(0.481-1.606) \\
\end{array}$ & 0.675 & $\begin{array}{l}0.743 \\
(0.396-1.393) \\
\end{array}$ & 0.354 \\
\hline P for the trend & & & & 0.016 & & 0.005 \\
\hline \multicolumn{7}{|l|}{ Duration } \\
\hline Never & 158 & 159 & 1 & & 1 & \\
\hline Short & 61 & 8 & $\begin{array}{l}0.130 \\
(0.060-0.281)\end{array}$ & $<0.001$ & $\begin{array}{l}0.139 \\
(0.063-0.305)\end{array}$ & $<0.001$ \\
\hline Moderate & 122 & 35 & $\begin{array}{l}0.285 \\
(0.184-0.441)\end{array}$ & $<0.001$ & $\begin{array}{l}0.271 \\
(0.173-0.426)\end{array}$ & $<0.001$ \\
\hline Long & 59 & 38 & $\begin{array}{l}0.640 \\
(0.403-1.017)\end{array}$ & 0.059 & $\begin{array}{l}0.532 \\
(0.326-0.867)\end{array}$ & 0.011 \\
\hline $\mathrm{P}$ for the trend & & & & $<0.001$ & & $<0.001$ \\
\hline
\end{tabular}

$\mathrm{AF}$, atrial fibrillation; OR, odds ratio; CI, confidence interval;

1. In frequency, group was categorized as low (<1cup/day) moderate (1cup/day) and high ( $>1 \mathrm{cup} /$ day $)$.

2. In concentration, group was categorized as low (tea leaves were $<25 \%$ of the volume of the cup), moderate (tea leaves were

$25-50 \%$ of the volume of the cup) and high (tea leaves were $>50 \%$ of the volume of the cup).

3 . In duration, group was categorized as short (1-15Y) moderate $(16-30 \mathrm{Y})$ and long $(>30 \mathrm{Y})$.

4. Adjustment for age, gender, body mass index, smoking status, alcohol use, physical activity, hypertension, hyperlipidemia, diabetes mellitus, and CAD in the analysis.

These results suggest that low-dose green tea induces a strong protective effect and increasing tea consumption weakens this protection.

Subsequently, we divided participants according to different AF types. We found green tea intake is linearly correlated with decreased incidence of both paroxysmal $\mathrm{AF}$ and persistent $\mathrm{AF}$, with an adjustment $\mathrm{OR}$ less than 1. However, green tea intake is not associated with permanent AF. The paroxysmal and the persistent AF were in the early and middle stages of oxidative stress, inflammation, fibrosis and alteration of electrophysiology [52]. As such, EGCG may result in an anti-inflammatory, anti-oxidation, and anti-fibrosis effect. Participants with permanent $\mathrm{AF}$ displayed severe electrophysiological and organic changes [53], which may preclude any benefit of green tea. We found that increased frequency, concentration, and duration of green tea intake had a negative correlation with protection from paroxysmal AF, which is consistent with the overall results, but a positive correlation with protection of persistent AF. It has been reported that caffeine does not affect prevailing cardiac rhythm and rate in healthy adults [54]. Moreover, elevated levels of sympathetic activity have been shown to be detrimental $[51,55]$. Thus, while caffeine intake might be associated with increased incidence of AF, data remains inconclusive at this point in time [49]. Persistent AF risk for patients decreased with the increasing frequency, duration and concentration of green tea consumed. When AF becomes persistent, it is changed and associated with atrial enlargement and structural changes [56-57], 
Table 8: Relationship between green tea intake and risk of persistent $\mathrm{AF}$;

\begin{tabular}{|c|c|c|c|c|c|c|}
\hline Characteristics & \begin{tabular}{|l|} 
Controls \\
$(N=400)$
\end{tabular} & Persistent $\operatorname{AF}(N=72)$ & Crude OR & $P$ & Adjusted OR & $P$ \\
\hline \multicolumn{7}{|l|}{ Tea $(\mathrm{Y} / \mathrm{N})$} \\
\hline 0 & 158 & 48 & 1 & & 1 & \\
\hline 1 & 242 & 24 & \begin{tabular}{|l|}
0.326 \\
$(0.192-0.554)$ \\
\end{tabular} & $<0.001$ & \begin{tabular}{|l|}
0.304 \\
$(0.175-0.527)$ \\
\end{tabular} & $<0.001$ \\
\hline \multicolumn{7}{|l|}{ Frequency } \\
\hline None & 158 & 48 & 1 & & 1 & \\
\hline Low & 37 & 7 & \begin{tabular}{|l|}
0.623 \\
$(0.261-1.486)$ \\
\end{tabular} & 0.286 & $\begin{array}{l}0.715 \\
(0.289-1.768) \\
\end{array}$ & 0.468 \\
\hline Moderate & 188 & 15 & \begin{tabular}{|l|}
0.263 \\
$(0.142-0.487)$ \\
\end{tabular} & $<0.001$ & \begin{tabular}{|l}
0.235 \\
$(0.124-0.447)$ \\
\end{tabular} & $<0.001$ \\
\hline High & 17 & 2 & \begin{tabular}{|l|}
0.387 \\
$(0.086-1.736)$ \\
\end{tabular} & 0.215 & $\begin{array}{l}0.318 \\
(0.068-1.495) \\
\end{array}$ & 0.147 \\
\hline $\mathrm{P}$ for the trend & & & & $<0.001$ & & $<0.001$ \\
\hline \multicolumn{7}{|l|}{ Concentration } \\
\hline None & 158 & 48 & 1 & & 1 & \\
\hline Low & 193 & 17 & $\begin{array}{l}0.290 \\
(0.160-0.524) \\
\end{array}$ & $<0.001$ & \begin{tabular}{|l|}
0.291 \\
$(0.158-0.535)$ \\
\end{tabular} & $<0.001$ \\
\hline Moderate & 23 & 5 & \begin{tabular}{|l|}
0.716 \\
$(0.258-1.984)$ \\
\end{tabular} & 0.520 & $\begin{array}{l}0.506 \\
(0.174-1.475) \\
\end{array}$ & 0.212 \\
\hline High & 26 & 2 & $\begin{array}{l}0.253 \\
(0.058-1.106) \\
\end{array}$ & 0.068 & $\begin{array}{l}0.190 \\
(0.042-0.869)\end{array}$ & 0.032 \\
\hline $\mathrm{P}$ for the trend & & & & 0.002 & & 0.001 \\
\hline \multicolumn{7}{|l|}{ Duration } \\
\hline Never & 158 & 48 & 1 & & 1 & \\
\hline Short & 61 & 7 & $\begin{array}{l}0.378 \\
(0.162-0.880)\end{array}$ & 0.024 & $\begin{array}{l}0.398 \\
(0.166-0.954)\end{array}$ & 0.039 \\
\hline Moderate & 122 & 13 & $\begin{array}{l}0.351 \\
(0.182-0.676)\end{array}$ & 0.002 & $\begin{array}{l}0.333 \\
(0.168-0.657)\end{array}$ & 0.002 \\
\hline Long & 59 & 4 & $\begin{array}{l}0.223 \\
(0.077-0.646)\end{array}$ & 0.006 & $\begin{array}{l}0.175 \\
(0.058-0.524)\end{array}$ & 0.002 \\
\hline $\mathrm{P}$ for the trend & & & & $<0.001$ & & $<0.001$ \\
\hline
\end{tabular}

$\mathrm{AF}$, atrial fibrillation; OR, odds ratio; $\mathrm{CI}$, confidence interval;

1. In frequency, group was categorized as low ( $<1$ cup/day) moderate (1cup/day) and high ( $>1 \mathrm{cup} /$ day).

2. In concentration, group was categorized as low (tea leaves were $<25 \%$ of the volume of the cup), moderate (tea leaves were

$25-50 \%$ of the volume of the cup) and high (tea leaves were $>50 \%$ of the volume of the cup).

3. In duration, group was categorized as short (1-15Y) moderate (16-30Y) and long ( $>30 \mathrm{Y})$.

4. Adjustment for age, gender, body mass index, smoking status, alcohol use, physical activity, hypertension, hyperlipidemia, diabetes mellitus, and CAD in the analysis.

and increasing fibrosis [58], which could enhance the protective role of EGCG for some unknown reason.

Our study supports low-dose green tea intake as a means of protecting against persistent AF and paroxysmal AF. The underlying mechanism by which green tea affects its function in reducing the incidence of $\mathrm{AF}$ will require further experimental studies.

\section{Advantages and limitations}

To the best of our knowledge, this work represents the first study on the association between green tea intake and the incidence of $\mathrm{AF}$. We interpreted the relation between green tea and different types of $\mathrm{AF}$ with a consistent conclusion that green tea, especially when consumed in small amounts, provides a protective effect. These observations may aid in the prevention of the occurrence of AF or protection after its occurrence in clinical practice activities.

There are, however, several potential limitations in this research. First, our research was a cross-sectional, single-center observational study with a relatively small sample size. Thus, these results need to be validated in a large-scale, multi-center prospective study. Second, our study was a retrospective case-control study and thus susceptible to various biases. Green tea intake was assessed by the number of cups consumed daily or weekly, however, the size of cups was not uniform. Moreover, 
memory bias is inevitable and uncontrolled confounders cannot be ruled out as a potential effect on the relationship between green tea intake and incidence of AF; such confounders could include coffee consumption, drug and herbal medicine intake, and psychological factors. Third, screening electrocardiograms were performed only once, and it is possible that asymptomatic AF may have gone undetected in the control group. Fourth, we have not yet confirmed the mechanism by which green tea exerts its protective role. Finally, our study was based entirely on a Chinese population; it is uncertain whether the results can be extrapolated to other populations.

In conclusion, green tea drinking appears to be independently associated with lower incidence of AF in this large cohort of Chinese patients. Our results suggest that low-dose green tea intake could provide a protective effect; however, additional multi-center large-scale prospective cohort studies are required to validate our results. Ultimately, the association between routine intake of green tea and reduced incidence of AF is promising and warrants further research.

\section{MATERIALS AND METHODS}

\section{Participants}

Eight-hundred one $(n=801)$ participants (480 males and 321 females) between the ages of 17 and 89 were recruited from First Affiliated Hospital of Nanjing Medical University from September 2014 to October 2015. This study was approved by the Ethics Committee of the First Affiliated Hospital of Nanjing Medical University, Jiangsu Province, China, and written informed consent was received from each patient. The study of green tea intake and AF was in accordance with approved institutional guidelines. Eligible participants diagnosed with AF were randomly recruited as a case group. We collected information via a questionnaire, which was distributed to 650 patients and completed by 469 individuals. To minimize bias, we ruled out 30 patients without reliably confirmed disease and the possibility of secondary AF, including patients with history of valvular disease $(n=$ $6)$, cardiomyopathy $(n=9)$, congenital heart disease ( $n$ $=4)$, and hyperthyroidism $(n=8)$. Finally, the case group consisted of 401 participants (241 males and 160 females), and 400 (239 males and 161 females) individuals without history of AF as the control group.

\section{Ascertainment of incidence of AF}

AF patients enrolled in the investigation presented with a history of paroxysmal AF as documented by electrocardiography and AF details collected through review of medical records with informed consent. Subjects were divided into the following 4 groups: 1) no AF; 2) paroxysmal AF; 3) persistent AF; and 4) permanent AF.

If the arrhythmia terminated spontaneously and within 7 days, AF was designated as paroxysmal; and when sustained beyond 7 days or terminated by pharmacological or electrical cardioversion, AF was deemed persistent. Persistent AF also includes cases of longstanding AF, usually leading to permanent AF, in which cardioversion has failed or has been foregone [59$60]$.

\section{Assessment of green tea intake and other covariates}

Information on green tea intake and other baseline covariates were collected via questionnaire on the 801 participants. Participants were divided into 2 groups based on their response to the question 'Do you drink green tea?' (Y/N). The yes-group was followed up with several questions which included: (1) How often do you drink green tea each week? (2) How long have you been drinking tea? (3) What concentration of green tea do you usually consume? Based on the answers provided we created 4 categories of frequency: none, $<1,1$, and $>1$ cup/week, and 4 categories of duration: none, $<15,16-$ $30,>30$ years. The concentration was divided into low (green tea leaves were $<25 \%$ of the wet volume of the cup), moderate (green tea leaves were $25-50 \%$ of the wet volume of the cup) and high (green tea leaves were $>50 \%$ of the wet volume of the cup) [23]. The frequency of green tea intake was rated on a 3-point scale ranging from low $=$ " 1 " to high = " 3 ", the same to concentration and duration accordingly. According to the final score, the green tea drinker was divided into 7 groups ranging from " 3 " to "9". Accordingly, we defined the group of 3 points as low-dose green tea intake of group.

The clinical characteristics of participants were collected, including age (in years), gender (male, female), BMI (calculated from height and weight; in $\mathrm{kg} / \mathrm{m}^{2}$ ), physical activity $(\mathrm{Y} / \mathrm{N})$, smoking status $(\mathrm{Y} / \mathrm{N})$, alcohol consumption $(\mathrm{Y} / \mathrm{N})$, physician-diagnosed hypertension $(\mathrm{Y} / \mathrm{N})$, physician-diagnosed diabetes mellitus $(\mathrm{Y} / \mathrm{N})$, physician-diagnosed hyperlipoidemia $(\mathrm{Y} / \mathrm{N})$, and physician-diagnosed coronary heart disease $(\mathrm{Y} / \mathrm{N})$.

\section{Statistical analyses}

Statistical analysis was conducted using Statistics Package for Social Sciences (ver. 16.0; SPSS Incorporated, Chicago, IL, USA). We analyzed the basic characteristics of the overall data. Continuous variables of age and BMI were normally distributed and are presented as mean \pm SD. The comparisons were analyzed using variance analysis. Sex, smoking status, drinking status, physical activity, CHD status, diabetes status, hypertension status, 
and hyperlipoidemia status were treated as categorical variables and compared among the groups of patients using chi-squared analyses. We used univariate and multiple logistic regression analyses to access and exclude various factors influencing the interference. To facilitate analysis, we regarded non-tea drinkers as the reference group, and categorized all green tea intake variables, except the response to 'do you drink green tea $(\mathrm{Y} / \mathrm{N})$ ?', into several levels [61]. We calculated odds ratios (ORs) and 95\% confidence intervals (CIs) to express the association, and each quantitative categorization of green tea intake was subjected to a linear trend test. Subsequently, AF patients were grouped according to their classification (paroxysmal, persistent, or permanent) of AF, as previously described. We calculated ORs and 95\% CIs and conducted a linear trend test to reveal the association between green tea intake and different types of AF.

\section{CONFLICTS OF INTEREST}

The authors reveal no conflicts of interest.

\section{FINANCIAL SUPPORT}

This work was supported by grants from the National Natural Science Foundation of China (No $81270255 \& 81570363$ ) and a Project Funded by the Priority Academic Program Development of Jiangsu Higher Education Institutions (PAPD).

\section{REFERENCES}

1. Braunwald E. Shattuck lecture-cardiovascular medicine at the turn of the millennium: triumphs, concerns, and opportunities. The New England journal of medicine. 1997; 337(19): 1360-9.

2. Chugh SS, Blackshear JL, Shen WK, Hammill SC, and Gersh BJ. Epidemiology and natural history of atrial fibrillation: clinical implications. Journal of the American College of Cardiology. 2001; 37(2): 371-8.

3. Vaidya PN, Bhosley PN, Rao DB, and Luisada AA. Tachyarrhythmias in old age. Journal of the American Geriatrics Society. 1976; 24(9): 412-4.

4. Flegel KM, and Hanley J. Risk factors for stroke and other embolic events in patients with nonrheumatic atrial fibrillation. Stroke. 1989; 20(8): 1000-4.

5. Wolf PA, Dawber TR, Thomas HE, Jr., and Kannel WB. Epidemiologic assessment of chronic atrial fibrillation and risk of stroke: the Framingham study. Neurology. 1978; 28(10): 973-7.

6. Falk RH. Atrial fibrillation. The New England journal of medicine. 2001; 344(14): 1067-78.

7. Lu Y, Zhang Y, Wang N, Pan Z, Gao X, Zhang F, Zhang Y, Shan H, Luo X, Bai Y, Sun L, Song W, Xu C, et al.
MicroRNA-328 contributes to adverse electrical remodeling in atrial fibrillation. Circulation. 2010; 122(23): 2378-87.

8. Nattel S. Atrial electrophysiological remodeling caused by rapid atrial activation: underlying mechanisms and clinical relevance to atrial fibrillation. Cardiovascular research. 1999; 42(2): 298-308.

9. Nattel S. New ideas about atrial fibrillation 50 years on. Nature. 2002; 415(6868): 219-26.

10. Chou CC, Nihei M, Zhou S, Tan A, Kawase A, Macias ES, Fishbein MC, Lin SF, and Chen PS. Intracellular calcium dynamics and anisotropic reentry in isolated canine pulmonary veins and left atrium. Circulation. 2005; 111(22): 2889-97.

11. Fuster V, Rydén LE, Cannom DS, Crijns HJ, Curtis AB, Ellenbogen KA, Halperin JL, Le Heuzey JY, Kay GN, Lowe JE, Olsson SB, Prystowsky EN, Tamargo JL, et al; ACC/AHA/ESC 2006 guidelines for the management of patients with atrial fibrillation - executive summary: a report of the American College of Cardiology/American Heart Association Task Force on Practice Guidelines and the European Society of Cardiology Committee for Practice Guidelines (Writing Committee to Revise the 2001 Guidelines for the Management of Patients With Atrial Fibrillation).. Journal of the American College of Cardiology. 2006; 48(4): 854-906.

12. Benjamin EJ, Chen PS, Bild DE, Mascette AM, Albert CM, Alonso A, Calkins H, Connolly SJ, Curtis AB, Darbar D, Ellinor PT, Go AS, Goldschlager NF, et al. Prevention of atrial fibrillation: report from a national heart, lung, and blood institute workshop. Circulation. 2009; 119(4): 60618.

13. Conen D, Chiuve SE, Everett BM, Zhang SM, Buring JE, and Albert CM. Caffeine consumption and incident atrial fibrillation in women. The American journal of clinical nutrition. 2010; 92(3): 509-14.

14. Artin B, Singh M, Richeh C, Jawad E, Arora R, and Khosla S. Caffeine-related atrial fibrillation. American journal of therapeutics. 2010; 17(5): e169-71.

15. Mattioli AV, Farinetti A, Miloro C, Pedrazzi P, and Mattioli G. Influence of coffee and caffeine consumption on atrial fibrillation in hypertensive patients. Nutr Metab Cardiovasc Dis. 2011; 21(6): 412-7.

16. Larsson SC, Drca N, and Wolk A. Alcohol consumption and risk of atrial fibrillation: a prospective study and doseresponse meta-analysis. Journal of the American College of Cardiology. 2014; 64(3): 281-9.

17. Kodama S, Saito K, Tanaka S, Horikawa C, Saito A, Heianza Y, Anasako Y, Nishigaki Y, Yachi Y, Iida KT, Ohashi Y, Yamada N, and Sone H. Alcohol consumption and risk of atrial fibrillation: a meta-analysis. Journal of the American College of Cardiology. 2011; 57(4): 427-36.

18. Samokhvalov AV, Irving HM, Rehm J. Alcohol consumption as a risk factor for atrial fibrillation: a systematic review and meta-analysis. Eur J Cardiovasc Prev 
Rehabil. 2010; 17(6): 706-12.

19. Qiao Y, Shi R, Hou B, Wu L, Zheng L, Ding L, Chen G, Zhang S, and Yao Y. Impact of Alcohol Consumption on Substrate Remodeling and Ablation Outcome of Paroxysmal Atrial Fibrillation. Journal of the American Heart Association. 2015; 4(11). pii: e002349. doi:10.1161/ JAHA. 115.002349

20. Graham HN. Green tea composition, consumption, and polyphenol chemistry. Preventive medicine. 1992; 21(3): 334-50.

21. Wang ZM, Zhou B, Wang YS, Gong QY, Wang QM, Yan JJ, Gao W, and Wang LS. Black and green tea consumption and the risk of coronary artery disease: a meta-analysis. The American journal of clinical nutrition. 2011; 93(3): 506-15.

22. McKay DL, and Blumberg JB. The role of tea in human health: an update. Journal of the American College of Nutrition. 2002; 21(1): 1-13.

23. Wang QM, Gong QY, Yan JJ, Zhu J, Tang JJ, Wang MW, Yang ZJ, and Wang LS.. Association between green tea intake and coronary artery disease in a Chinese population. Circ J. 2010; 74(2): 294-300.

24. Babu PV, and Liu D. Green tea catechins and cardiovascular health: an update. Current medicinal chemistry. 2008; 15(18): 1840-50.

25. Pang J, Zhang Z, Zheng T, Yang YJ, Li N, Bai M, Peng Y, Zhang J, Li Q, and Zhang B. Association of green tea consumption with risk of coronary heart disease in Chinese population. International journal of cardiology. 2015; 179: 275-8.

26. Sesso HD, Paffenbarger RS Jr, Oguma Y, and Lee IM. Lack of association between tea and cardiovascular disease in college alumni. International journal of epidemiology. 2003; 32(4): 527-33.

27. Wang ZM, Gao W, Wang H, Zhao D, Nie ZL, Shi JQ, Zhao S, Lu X, Wang LS, and Yang ZJ. Green tea polyphenol epigallocatechin-3-gallate inhibits TNF-alpha-induced production of monocyte chemoattractant protein-1 in human umbilical vein endothelial cells. Cell Physiol Biochem. 2014; 33(5): 1349-58.

28. Hertog MG, Feskens EJ, Hollman PC, Katan MB, and Kromhout D. Dietary antioxidant flavonoids and risk of coronary heart disease: the Zutphen Elderly Study. Lancet. 1993; 342(8878): 1007-11.

29. Zeng X, Li Q, Zhang M, Wang W, and Tan X. Green tea may be benefit to the therapy of atrial fibrillation. J Cell Biochem. 2011; 112(7):1709-12.

30. Pang J, Zhang Z, Zheng TZ, Bassig BA, Mao C, Liu X, Zhu Y, Shi K, Ge J, Yang YJ, Dejia-Huang, Bai M, and Peng Y. Green tea consumption and risk of cardiovascular and ischemic related diseases: A meta-analysis. Int J Cardiol. 2016; 202:967-74.

31. Greyling A, Ras RT, Zock PL, Lorenz M, Hopman MT, Thijssen DH, and Draijer R. The effect of black tea on blood pressure: a systematic review with meta-analysis of randomized controlled trials. PLoS One. 2014; 9(7):e103247.

32. Korantzopoulos P, Kolettis TM, Galaris D, and Goudevenos JA. The role of oxidative stress in the pathogenesis and perpetuation of atrial fibrillation. International journal of cardiology. 2007; 115(2): 135-43.

33. Verma A, Wazni OM, Marrouche NF, Martin DO, Kilicaslan F, Minor S, Schweikert RA, Saliba W, Cummings J, Burkhardt JD, Bhargava M, Belden WA, Abdul-Karim A, et al . Pre-existent left atrial scarring in patients undergoing pulmonary vein antrum isolation: an independent predictor of procedural failure. Journal of the American College of Cardiology. 2005; 45(2): 285-92.

34. Korantzopoulos P, and Goudevenos JA. Aldosterone signaling in atrial fibrillation another piece in the puzzle of atrial remodeling. Journal of the American College of Cardiology. 2010; 55(8): 771-3.

35. Liao JK. Rac1 and connective tissue growth factor. The missing link between atrial remodeling and the pathogenesis of atrial fibrillation? Journal of the American College of Cardiology. 2010; 55(5): 481-2.

36. Frustaci A, Chimenti C, Bellocci F, Morgante E, Russo MA, and Maseri A. Histological substrate of atrial biopsies in patients with lone atrial fibrillation. Circulation. 1997; 96(4): 1180-4.

37. Guo Y, and Lip GY, Apostolakis S. Inflammation in atrial fibrillation. Journal of the American College of Cardiology. 2012; 60(22): 2263-70.

38. Burstein B, and Nattel S. Atrial fibrosis: mechanisms and clinical relevance in atrial fibrillation. Journal of the American College of Cardiology. 2008; 51(8): 802-9.

39. Issac TT, Dokainish H, and Lakkis NM. Role of inflammation in initiation and perpetuation of atrial fibrillation: a systematic review of the published data. Journal of the American College of Cardiology. 2007; 50(21): 2021-8.

40. Qu YC, Du YM, Wu SL, Chen QX, Wu HL, and Zhou $\mathrm{SF}$. Activated nuclear factor-kappaB and increased tumor necrosis factor-alpha in atrial tissue of atrial fibrillation. Scandinavian cardiovascular journal. 2009; 43(5): 292-7.

41. Wu N, Xu B, Xiang Y, Wu L, Zhang Y, Ma X, Tong S, Shu M, Song Z, Li Y, and Zhong L. Association of inflammatory factors with occurrence and recurrence of atrial fibrillation: a meta-analysis. International journal of cardiology. 2013; 169(1): 62-72.

42. Nyrnes A, Njølstad I, Mathiesen EB, Wilsgaard T, Hansen JB, Skjelbakken T, Jørgensen L, and Løchen ML. Inflammatory biomarkers as risk factors for future atrial fibrillation. An eleven-year follow-up of 6315 men and women: the Tromso study. Gender medicine. 2012; 9(6): 536-47 e2.

43. Shahidi F. Antioxidants in food and food antioxidants. Die Nahrung. 2000; 44(3): 158-63.

44. Islam MA. Cardiovascular effects of green tea catechins: 
progress and promise. Recent patents on cardiovascular drug discovery. 2012; 7(2): 88-99.

45. Yang J, Han Y, Chen C, Sun H, He D, Guo J, Jiang B, Zhou L, and Zeng C. EGCG attenuates high glucose-induced endothelial cell inflammation by suppression of PKC and NF-kappaB signaling in human umbilical vein endothelial cells. Life sciences. 2013; 92(10): 589-97.

46. Liu D, Perkins JT, and Hennig B. EGCG prevents PCB126-induced endothelial cell inflammation via epigenetic modifications of NF-kappaB target genes in human endothelial cells. The Journal of nutritional biochemistry. 2016; 28: 164-70.

47. Ras RT, Zock PL, and Draijer R. Tea consumption enhances endothelial-dependent vasodilation; a meta-analysis. PLoS One. 2011; 6(3):e16974.

48. Zhu J, Zhang X, Li L, and Su G. Protective effects of epigallocatechin-3 gallate on atrial electrical and structural remodeling in a rabbit rapid atrial pacing model. Cell biochemistry and biophysics. 2015; 71(2): 897-903.

49. Caldeira D, Martins C, Alves LB, Pereira H, Ferreira JJ, and Costa J. Caffeine does not increase the risk of atrial fibrillation: a systematic review and meta-analysis of observational studies. Heart. 2013; 99(19): 1383-9.

50. Frost L, Vestergaard P. Caffeine and risk of atrial fibrillation or flutter: the Danish Diet, Cancer, and Health Study. The American journal of clinical nutrition. 2005; 81(3): 578-82.

51. Li Y, Lu Z, Tang Q, Jiang H, Huang C, He B, Hu X, Huang $\mathrm{J}$, Zhu X, and Wang H. The increase in sympathetic nerve density in the atrium facilitates atrial fibrillation in patients with rheumatic heart disease. International journal of cardiology.2013; 165(1): 174-8.

52. Matějková A, Šteiner I. Association of Atrial Fibrillation with Morphological and Electrophysiological Changes of the Atrial Myocardium. Acta Medica (Hradec Kralove). 2016; 59(2):43-9.

53. Kawai S, Ih S, Koizumi K. Pathology of atrial fibrillation. J Cardiol. 1999; 33 Suppl 1:47-52.

54. Newcombe PF, Renton KW, Rautaharju PM, Spencer CA, and Montague TJ. High-dose caffeine and cardiac rate and rhythm in normal subjects. Chest 1988; 94(1): 90-4.
55. Wasmund SL, Li JM, Page RL, Joglar JA, Kowal RC, Smith ML, and Hamdan MH. Effect of atrial fibrillation and an irregular ventricular response on sympathetic nerve activity in human subjects. Circulation. 2003; 107(15): 2011-5.

56. Morillo CA, Klein GJ, Jones DL, and Guiraudon CM. Chronic rapid atrial pacing. Structural, functional, and electrophysiological characteristics of a new model of sustained atrial fibrillation. Circulation. 1995; 91(5): 158895.

57. Okumura K. Extracellular matrix remodeling as a cause of persistent atrial fibrillation: another therapeutic target. Journal of cardiovascular electrophysiology. 2007; 18(10): 1083-5.

58. Adeniran I, MacIver DH, Garratt CJ, Ye J, Hancox JC, and Zhang H. Effects of Persistent Atrial Fibrillation-Induced Electrical Remodeling on Atrial Electro-Mechanics Insights from a 3D Model of the Human Atria. PloS one. 2015; 10(11): e0142397.

59. Lévy S, Camm AJ, Saksena S, Aliot E, Breithardt G, Crijns HJ, Davies DW, Kay GN, Prystowsky EN, Sutton $\mathrm{R}$, Waldo AL, and Wyse DG. International consensus on nomenclature and classification of atrial fibrillation: A collaborative project of the Working Group on Arrhythmias and the Working Group of Cardiac Pacing of the European Society of Cardiology and the North American Society of Pacing and Electrophysiology. Journal of cardiovascular electrophysiology. 2003; 14(4): 443-5.

60. Borleffs CJ, van Rees JB, van Welsenes GH, van der Velde ET, van Erven L, Bax JJ, and Schalij MJ. Prognostic importance of atrial fibrillation in implantable cardioverterdefibrillator patients. Journal of the American College of Cardiology. 2010; 55(9): 879-85.

61. Mu LN, Lu QY, Yu SZ, Jiang QW, Cao W, You NC, Setiawan VW, Zhou XF, Ding BG,Wang RH, Zhao J, Cai $\mathrm{L}$, Rao JY, et al. Green tea drinking and multigenetic index on the risk of stomach cancer in a Chinese population. International journal of cancer. 2005; 116(6): 972-83. 